\title{
THE ROLE OF INTERCULTURAL SIMULATION GAMES IN THE STUDY PROCESS: THE IMPACT ON THE DEVELOPMENT OF INTERCULTURAL COMPETENCE
}

\author{
Eglė Gerulaitienė \\ Siauliai University
}

\begin{abstract}
Intercultural simulation games are defined as instructional activities that engage and challenge participants with certain experiences. The use of intercultural simulation games in the study process while developing intercultural competence becomes very essential part of education. The primary prerequisite for development of intercultural competence is multicultural environment and methods aimed at creation or simulation of real-life activity and situation. This article examines the conceptual bases for intercultural simulation games in the study process and its impact or efficacy on the development of intercultural competence. Intercultural simulation games are designed and conducted to develop skills and inoculate participants for future experience in a different or unknown cultural environment.
\end{abstract}

Keywords: intercultural simulation games, development of intercultural competence, Ecotonos, An Alien Among Us.

\section{Introduction}

The increasing role of intercultural simulation games as of educational resource has been noticed with the ongoing introduction of interactive experiential learning. Simulation games imitate real-life situations and allow learners feel as if they participate in real-life situations, experience real-life stress and problems, understand the complexity and implications of the reality. Practical testing and scientific analysis are required to see how the educational innovation changes the process of learning and, thereby, educational institution, interaction between participants of educational process and their roles, new competences it helps develop, as well as differences from other, traditional learning strategies and traditional resources and media (primarily, textbooks). Intercultural simulation games not only bring changes to educational interaction, but also are a certain kind of educational media.

Due to ongoing changes in social, technical, educational and other environment in the modern society, information, knowledge and abilities quickly outdate and the necessity to acquire lifelong learning and new abilities arises (Langner, Kaftan, 1999). According to Longworth (2000), learning as a natural and developing process has to turn into a pleasant and motivating activity, which takes place throughout all life and everywhere, empowering people to develop their personal skills and competences, ensuring self-confidence in the future. Today learning is no longer directly related to the process of teaching or education. The learner's provision with effective teaching aids that correspond to the learning style and needs is emphasized. Thus, it is progressed from the teaching paradigm to the learning paradigm, from knowledge based approach to 
competence based approach and from subject based assessment to student based assessment. Traditional conception of teaching and learning is replaced by modern: constructivist learning paradigm, describing learning as a process encompassing qualitative changes in students' thinking, feelings, perception and behaviour and highlighting the student's ability to see, experience and understand processes taking place in the real world and the possibility to create individual knowing, think and evaluate personal development (Teresevičienè et al. 2004; Sahlberg, 2006). The constructivist paradigm emphasizes creation of strategies for learning from personal experience and perception of reflection as an activating precondition of lifelong learning. The constructivist paradigm underlines learning in the natural social activity (i.e., collaborating and solving problems).

Based on the mentioned notion of the change of learning process, a question rises about how to choose the right educational techniques, educational tools and media to satisfy the modern mode of production and consumption and to form new institutional education experience in order to develop creative industries, to become able to create, transfer and buy aesthetic pleasure and pleasure of living, satisfaction and amusement in modern post-industrial society and the new economy. Intercultural simulation games as new techniques and medias of learning/teaching are ascribed with new meaning in this process aimed at overcoming the opposition between work and play by learning through play. It is important to consider how educational institution changes and what happens to the standardized effect of education if play becomes a pedagogical scenario and traditional texts are used in a new way to stimulate playability. The use of intercultural simulation games in the study process while developing intercultural competence becomes very essential part of education. The primary prerequisite for development of intercultural competence is multicultural environment and methods aimed at creation or simulation of real-life activity and situation.

The aim of this article is to analyze the role of intercultural simulation games as mediation tools in the study process and its impact on the development of intercultural competence, with reference to practical experience of application of simulation games aimed at education of intercultural competence in the process of higher education. It was studied the potential of simulation games as educational resources in developing intercultural competence by testing 2 simulation games: "An Alien Among Us" (Powers, 1999), "Ecotonos" (Saphiere, 2008).

The methods of the article are:

1) conceptual analysis of scientific literature;

2) focus group discussions with the students, who were participating in these intercultural simulation games. 


\section{The peculiarities of intercultural competence development while playing intercultural simulation games in the study process}

Development of intercultural competence is understood as a continuing process that involves such strategies as experiential learning, problem-based learning, collaborative learning, reflective learning and cognitive learning. All these learning strategies are aimed at development of knowledge, skills abilities and attitudes, and at application of prior knowledge in the process of education by creating real or simulated (based on simulation games) intercultural situations. Having performed scientific literature analysis and based on characteristics of constructivist learning paradigm, we have created a model of development of intercultural competence (Figure 1). The primary prerequisite for development of intercultural competence is multicultural environment and methods aimed at creation or simulation of real-life activity and situation.

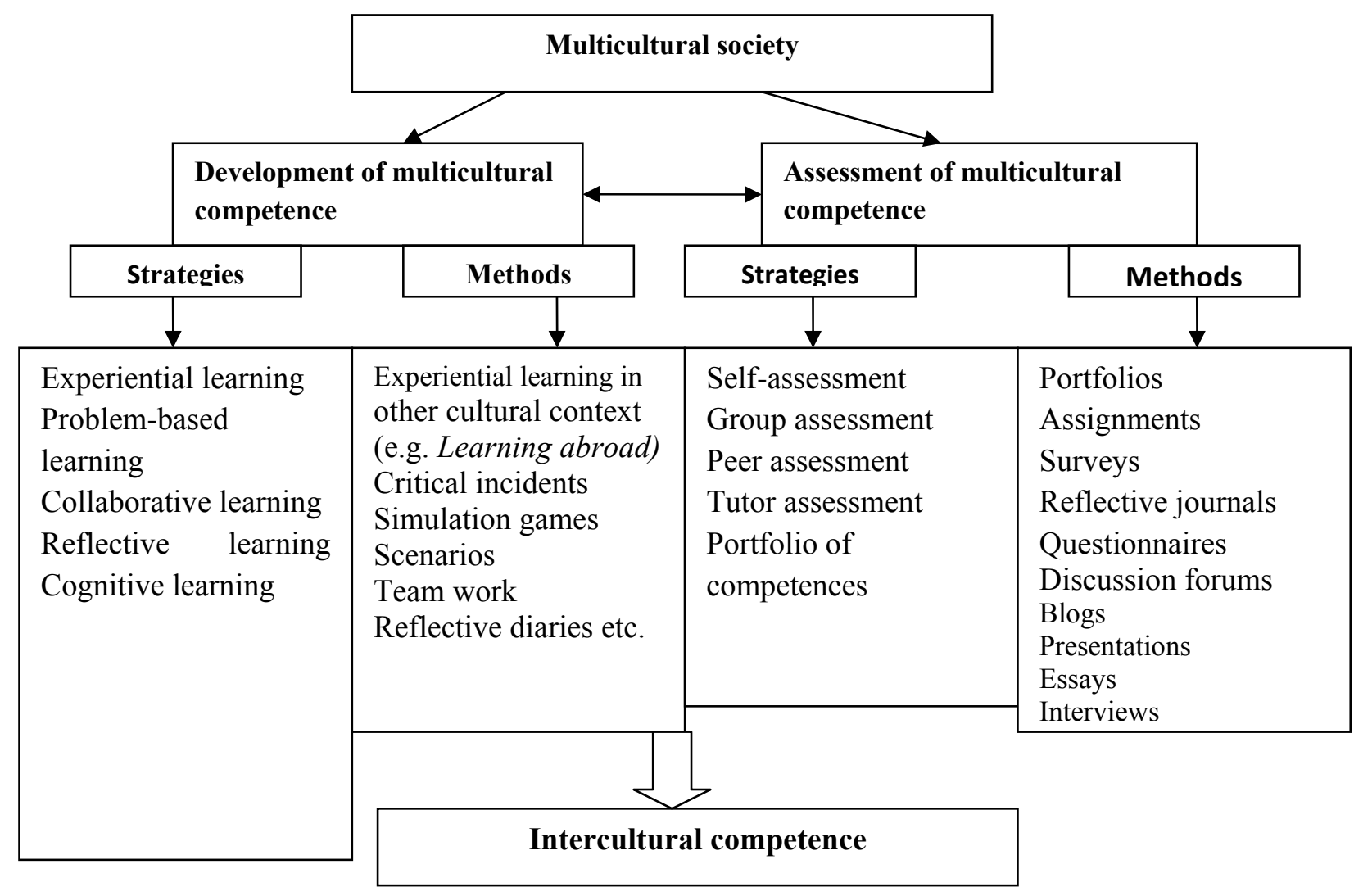

Fig. 1 Model of development of intercultural competence

Active experiential learning is an important source of students' skills as it helps students stop being passive consumers and become active players developing both their skills and values, and attitudes. Students study their own attitudes and values during active learning. According to Meyers and Jones (1993), active learning is comprised of 3 closely interrelated factors: 
1) main elements (speaking, learning, reading, writing and reflection) - all 5 elements imply cognitive activities allowing students formulate target questions and combine prior and newly acquired knowledge;

2) learning strategies (small groups, group work, simulation games, discussions, problem solving, journaling);

3) learning resources used by a teacher to encourage and motivate students to join learning activity.

One of the most effective strategies of intercultural learning is experiential learning in different cultural context. Apparently, such learning generally corresponds to real-life situations and problems of cultural clashes; therefore, such situations create possibilities for development of skills abilities, application of knowledge and expression of emotions in real-life context. However, not always and not everyone is given access to opportunities of experiential learning in different cultural context during their studies. This is why conditions for experiential learning should be created in higher schools (by integrating simulation games with representatives of other cultures) when developing the strategy of internationalisation at home. By combining experiential learning with education and assessment methods prompting reflective action activities it becomes possible not only to expand the knowledge, abilities of learners and show expression of their emotions and attitudes to them, but also to watch and assess them, think about own level of competences and limitations. These assessment methods and tools allow assessing metacognitive aspect of intercultural competence, when a learner evaluates his/her own learning process and results.

Intercultural simulation games that have started to be widely used imitate, simulate situations of intercultural environment. Simulation games are certain created imaginary environments with specific rules, created fictional scenarios and roles and certain encouragements and motivations to start the game. According Hofstede, de Caluwé and Peters (Hofstede et al., 2010), there is the confluence of systemic knowledge, practice, emotional involvement, and social embeddedness in simulation games that creates the potential to achieve results that no other methods can match. Preconditions of learning concentrate in the social and emotional aspects. The main aim of such simulation games is to help learners learn how to act in various intercultural contexts, recognize identities of various cultures and specifics of intercultural interaction, experience cultural diversity and benefits and difficulties brought by it by playing the game, feeling the specifics of imagined cultures and experiencing possible situations of cultural clash. Thus, besides the element of play, the element of seriousness of activity is retained by seeking to learn something on a certain topic. Learning during simulation games is a rather difficult process that implies not only certain scenario and appropriate preparation, but also its performance, the process that provides conditions for learning (Figure 2): 


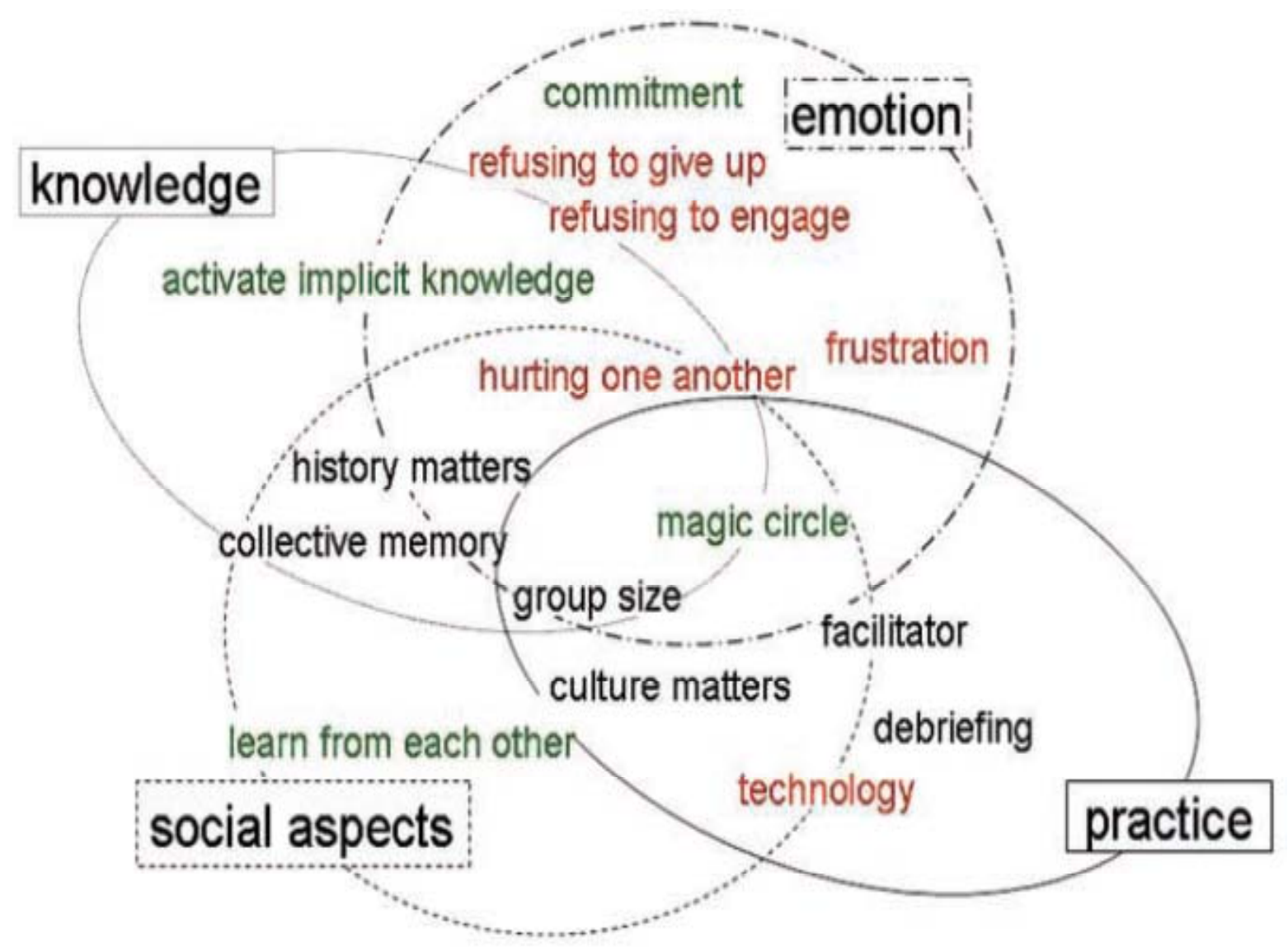

Fig. 2 Essential factors of simulation games (Hofstede et al., 2010).

Intercultural simulation games create multiple opportunities: to learn about oneself and own culture, to learn about others and evaluate one's experience of being with others, to try solve problems raising in the group, to find common solutions after hearing all team members' opinions and commentaries, to rediscover otherness and evaluate the concept of diversity. The main link connecting different simulation games is team work, activities work in separate small groups representing different cultures, organizations, groups/unions of people sharing common interests. The process of imitation created by simulation game implies that the players personally and/or in groups adopt the fictional cultural identity and experience interaction, clash or collaboration between people, groups of different cultural identities. Simulation games involve knowledge (about own/other cultures, geography, modes of behaviour), activity, emotions and social aspects. The most important participants in a game in a broader sense are game designers, facilitators, and players. The game itself should also be included in the list of important elements as a set of rules, game scenario, text and various tools.

According to the authors (Hofstede et al., 2010), successful results of a game are not secured or pre-given, they do not guarantee any pedagogical effect. The game in-the-box may differ largely from the game-in-use. The outcome of the 
game is related to certain unpredictability and there is risk to achieve no results, in which case the game fails. Failure may occur in various elements inappropriate scenario and game rules, unpredicted players' emotional expression, players' cultural background may determine unpredicted results, inadequate facilitation, failed debriefing etc. The process of any simulation game in action is unique - even if the same game is played in different groups, the result will be different because players' experiences, knowledge, attitudes, behaviour rules are different.

\section{Multiplicity and complexity of the rules in intercultural simulation games while creating different fictional cultural identities}

One of the main aims of simulation games is to create fictional cultural identities to be adopted by the players and to arrange situations of interplay and clash of the identities. Players play in groups and usually the necessary element of game is implemented - competition between players and groups, struggle for a prize and an award. Fictional intercultural environment is artificially created in the game - players become representatives and advocates of different cultures. Still, it is attempted to conceal the essential information to create the playful element of solving a riddle and the situation of cognitive curiosity. In order to imitate cultural identities and cultural clash, manipulation is used as one of characteristic uses of text in simulation games. To create the space of the game, players are provided with a text providing them with certain information. However, it is not equally easy for all the players to get access to important text, as the use of information is strictly regulated and rationed, not all players have the same possibilities to use the text, texts are differentiated, the text is not necessarily given to players in the same scope or with the same content. This is necessary in order to create different expertise and position of players to achieve different mode of thinking and decision making for creation of stress and frictions, different perspectives in assessment of the same things.

One of the games which clearly imitate the cultural clash between different cultural perspectives is the game called "An Alien Among Us" (Powers, 1999) which was tested. The game addresses one of the most important subjects of intercultural education - diversity. The aim of the game is to create opportunity of the players to make decision on the basis of their assessments of the otherness and diversity by categories - race, profession, age, religion etc. Game mechanism helps develop one of the essential elements of intercultural competences, i.e. ability to compare different cultures, and cultural awareness (according to Byram (1997), cultural awareness is an ability to evaluate critically and on the basis of explicit criteria perspectives, practices and products in one's own and other cultures and countries). 
Game scenario presents unreal, imagined and even fictional story about a creature called Zor-Zeva from another planet Bora-X5 that chooses 6 humans from 12 to represent the Earth when they are sent to Bora-X5. Players are offered to guess argumentation and choice of the creature Zor-Zeva and give own versions of which of the 12 candidates could be sent to another planet. Players are offered to evaluate the candidates by the criteria of diversity - race, age, health condition, occupation, religion, attitudes. The game provides a complex concept of diversity, aims at helping learners understand the intersectional idea that the categories of diversity (race, age, health condition, profession etc.) in a certain person merge into rather complex combinations, which makes selection of candidates very difficult and ambiguous process. By discussing in groups, the players may decide what information they require and what information is not necessary.

One of the interesting elements of organization of the game process that ensures pedagogical effect is that organization of the game implies separating ordinary players from expert players. The "expert" team of students (about 5 people) receives long texts containing additional detailed explanation about the importance of diversity for the inhabitants of planet Bora-X5. Additional information about diversity expands the knowledge and understanding of the "experts", they are presented with additional perspective of evaluating and seeing - they know not only about the arguments and interests of the humans, but also the motives and understanding of the aliens from another planet. Unlike other,"non-expert", participants, these "expert" players know more e.g. they have full information about all the candidates (they have received complete information about the candidates) and they do not need to "buy information", count and save points. Decisions made by the "expert" team later become the basis for evaluating other teams. "Non-expert" teams (the majority of the players) are not provided with texts about importance of diversity and possible perspective other planet may have. Hence, this "non-expert" group becomes a "natural" groups of representatives of the humans: they are what they really are - the humans of the Earth. The only text this group possesses is a brief explanation about the intentions of the aliens to select humans and an empty table of candidates.

However, in the case of held game sessions, though the so-called team of experts was given more information and broader perspective of cultural assessment and understanding of the importance of diversity as planned by the creators of the game, they still failed to fully avoid the "ethnocentric perspective" of the humans on the Earth. Both the "experts" and the "nonexperts" defined the category of occupation as the highest priority of candidate selection (what seemed important to the humans for the trip to another planet to be useful) and failed to evaluate the categories of diversity that would be important to the inhabitants of another planet. Decision about the candidates made by all of the groups of students was not in favour of and, we could say, 
discriminatory towards people of certain ages and weaker health. Thus, though the "expert" group's knowledge about the diversity expanded, they did not rise to a higher level of intercultural competence in their decision making. Trying to end the game and achieve the desired pedagogical effect, teachers held discussion with the students on the importance of diversity during the debriefing stage. This means that teachers as the ones who can create the zone of proximal development must use this opportunity during debriefing if the result is not achieved as planned during the game (by turning other students into more capable and more competent peers).

Another text used to create and imitate cultural clash can be found in the game of "Ecotonos" (Saphiere, 2008). The aim of the game is to make decisions based on diversity and way of thinking of other cultures and, by communicating in groups, provide students with possibility to experience various emotions in solving a given problem. According to the game scenario, players face an imagined, fictional plot without any particular introduction. The plot is presented in game cards; the players are divided into two or three groups/cultures. Groups of players are divided into fictional cultures - Zante, Delphinus, Aquila with different values and modes of behaviour. Players are offered to detach from their real cultural identities and adopt another, fictional, identity.

Teams are provided with cultural rule cards of general nature related to cultural dimensions and general features. Each group discusses and agrees on how they will enact their rules. Hence, the cards provide guidelines that must be followed by the players as the basis to communicate and collaborate with other cultures without knowing their rules in order to solve the given problems.

Players create more detailed rules of their cultures e.g. time planning, non-verbal behaviour, understanding of leadership - who could become the leader, how decisions are made etc. Players of each team, "culture", also create a story about their culture, a myth symbolizing their culture, a legend regarding how the culture was created. Storytelling is a very powerful tool, and helps the groups solidify. Later participants perform acculturation exercises - practice their rules and become accustomed to their cultures. At the beginning of the game, players feel uncomfortable as they transform into representatives of different, possibly inexistent culture. However, in the course of the game they get accustomed, start having fun believing that it is quire entertaining to behave as never before. After acculturation, each group is given a task (such as building a bridge or solving a case study) to work on, using their cultural rules. Before the groups are able to fully accomplish their task but after they are well into working on it, some participants are asked to move to another group, thus creating multicultural groups. The final step of the simulation is the multicultural problem solving, when participants attempt to complete their tasks in mixed groups. Players find themselves in extreme situation once again and they have to solve the situation together with representatives of other group, i.e. culture, who bring their culture 
rules with themselves and mess up the already routine identity. Creators of the game hope that once they mix cultures, players will hold to their original cultural rules with surprising rigidity.

In their attempt to jointly solve the problem (both of Zante and Delphinus cultures), the players face new feelings and emotions, unwillingness to accept other culture's proposals, rules; players tend to seriously argue and neither group wishes to compromise understanding that losing own identity once again would be very painful. The outcome of the game of "Ecotonos" differs from the one of "An Alien Among Us". No final winner is chosen during the game of "Ecotonos".

According to Fowler and Pusch (2010), this intercultural simulation game focuses on:

1. how to achieve resolution when there are many ways to approach and solvethe problem;

2. the impact of culture on any situation;

3. the need to reach solutions using the collective intelligence in a diverse group.

This game develops important elements of intercultural competence, such as ability to compare different cultures, ability to act in different cultural contexts. Important role is ascribed to abilities of conflict and problem solving, as well as personal characteristics, as the aim of the game is still to suddenly disbalance the players who find themselves in a very safe created fictional environment and introduce people of other cultural behaviour into that environment, at the same time splitting the groups and leaving no space for development of their created cultural identities. Thus, though there is no winner of the game, the major achievement is finding common solution to the given problem or conflict in multicultural environment and the feeling of common team pride.

Ecotonos implies the creative task of text creation and storytelling. Students learn not only to understand the text of culture through description and artefacts, but to be the creators of their stories, the authors of the fictional culture, the creators of their new identities.

\section{Conclusions}

Successful learning process is related to favourable educational environment, which distinguishes itself by high level of responsibility, possibility to express autonomy, access to necessary resources, tolerance for failures and quality feedback, enhancing students' belief in their abilities and encouraging students' motivation.

During practical testing of simulation games, it was noticed the potential of simulation games to educate important elements of intercultural competence and particular features of simulation games as of educational resources. These means help turn learning into play, which is a necessary component of cultural activity 
that reduces the gap between creative activity and rigorous and serious work, which would basically match the nature of modern post-industrial society.

Intercultural simulation games are oriented towards decision making skills and abilities to act in intercultural environment rather than knowledge (as emphasized by traditional educational text). A feature of simulation games as of educational resources and medias has been uncovered - organization of game implies text manipulations (concealing part of text, differentiating access of player groups to important texts) in order to artificially create cultural differences and cultural clashes, create different knowledge and understanding of the players. Intercultural simulation game as a unity of rules, texts and organization steps becomes a specific mediation tool that develops improvement of intercultural competence if certain interaction between participants (players and facilitators) is established. Intercultural simulation game forms different positions of players and facilitators, allows forming intercultural skills during interaction with facilitators (teachers) and more knowledgeable peers.

\section{Bibliography}

1. Byram, M. (1997). Teaching and Assessing Intercultural Communicative Competence. Clevedon: Multilingual Matters.

2. Fowler, S.M., \& Pusch, M.D. (2010). Intercultural simulation games: A review (of the United States and beyond). Simulation \& Gaming, 41, 94-115.

3. Hofstede G.J., Caluwé de L., and Peters V. (2010). Why Simulation Games Work-In Search of the Active Substance: A Synthesis. Simulation \& Gaming, 41(6) 824- 843.

4. Langner, A., Kaftan, N. (1999). Rethinking Knowledge - Labour. Education and Business in the Knowledge Society. Convention Booklet. OFW.

5. $\quad$ Longworth, N. (2000). Making Lifelong Learning Work: Learning Cities for a Learning Century. London: Kogan Page.

6. Meyer, C., \& Jones, T. B. (1993). Promoting active learning: Strategies for the college classroom. San Francisco: Jossey-Bass.

7. Powers, R.B. (1999). An Alien Among Us: A Diversity Game. Intercultural Press.

8. Sahlberg, P. (2006) Education reform for raising economic competitiveness. Journal of Educational Change, 7(3), 259-287.

9. Saphiere, D.H. (2008). Ecotonos: A Multicultural Problem Solving Simulation. Intercultural Press.

10. Teresevičienè, M., Oldroyd, D., Gedvilienè, G. (2004). Suaugusiuju mokymasis. Andragogikos didaktikos pagrindai. Kaunas: VDU.

\begin{tabular}{|l|l|}
\hline Eglė Gerulaitienè & Siauliai University \\
& Lithuania \\
& E-mail: e.virgailaite@cr.su.lt \\
\hline
\end{tabular}

